\title{
Solutions to Overcome Barriers of Implementing Constructability, Operability, and Maintainability (COM) Concepts in Infrastructure Projects: A Meta-Synthesis Approach
}

\author{
Omid Arbabi ${ }^{1}$, Ehsan Saghatforoush ${ }^{2}$, Hamidreza Athari Nikouravan ${ }^{3}$, Mohammad Mahoud ${ }^{4}$ \\ ${ }^{1}$ MSc Student, Department of Project and Construction Management, Mehralborz Institute of Higher Education, Tehran - \\ Iran \\ ${ }^{2}$ Assistant Professor, Department of Project and Construction Management, Mehralborz Institute of Higher Education, \\ Tehran - Iran. E-mail: e.saghatforoush@mehralborz.ac.ir (corresponding author). \\ ${ }^{3} \mathrm{PhD}$ Candidate, Project \& Management Degree, School of Architecture Tehran University, Tehran- Iran \\ ${ }^{4}$ MSc, Department of Project and Construction Management, Mehralborz Institute of Higher Education, Tehran - Iran
}

Project Management

Received November 21, 2016; received revisions February 5, 2017; February 20, 2017; accepted February 24, 2017

Available online March 13, 2017

\begin{abstract}
Construction managers in infrastructure projects in different societies offer and use approaches that can conclude each project's triangle of cost, time, and quality in the most optimal mode, satisfying important needs of the projects. One of these approaches is benefiting from concepts of Constructability, Operability, and Maintainability (the threefold concepts of COM), which can satisfy such need in infrastructure projects. In order to implement each approach, while the desired approach is innovative, as well, there are some barriers. It is significantly required to offer solutions to obtain desired results from that approach. Therefore, the aim of this research is presenting solutions to overcome existing barriers in implementing the threefold concepts of COM in infrastructure projects. For that, the Meta-Synthesis method is applied, which is placed in qualitative research category. In order to analyze collected data, descriptive and pattern coding techniques have been used. As the result of this study, a systematic classification of the solutions to overcome barriers of implementing the threefold concepts of COM in infrastructure projects is presented. The aim of construction managers is successful delivery of projects, for that, it is suggested to use such approaches that result in integration of different project life cycle phases. This facilitates optimization of project time and cost, aiming to provide a better quality of constructions. Therefore, in order to achieve infrastructure projects main objectives, such approaches are to be used, and in order to overcome barriers in implementing them, some solutions are to be identified, classified and presented.
\end{abstract}

Keywords: Solutions, overcome, barriers, implementation, constructability, operability, maintainability, infrastructure projects, meta-synthesis

\section{Introduction}

Infrastructures are among the most expensive projects in each country that can contribute in many jobs and guilds. Therefore, developing infrastructure projects is the economic growth engine of each society. Roads, rails, dams, houses, schools, health centers, and other infrastructures can be considered physical foundations that development and welfare in the modern life significantly depends on them. In developing infrastructures, it is important not only to maintain financial, but also social and environmental sustainability. In other words, infrastructures should be built in line with enhancing present needs, without endangering the future generation in satisfying their needs (Oxford Dictionary, 2009). Sustainable infrastructures should be designed and built to achieve their desired utilization, and also be maintained effectively and efficiently. Available methods and systems for construction, operation and maintenance have separated decisions made during planning and design phases (Trigunarsyah, 2001). Such separations in Project Life Cycle (PLC) phases cause neglecting many opportunities for huge savings in the construction project cost and time (Tatum, 1986).

Wells [4] showed that how separation among different phases of the project has made separation among different project stakeholders. Separation means isolating designers and planners from available lessons learned, knowledge, and experiences in construction, operation and maintenance phases. Integration is a factor for creating a long and effective competition, which increases talents and abilities for saving, enhancing, and improving money value (Alshawi and Faraj, 2002; Lennard et al., 2002). It can be concluded that "constructability, operability, and maintainability concepts are effective integration platforms for project owners to prevent problems due to delivering infrastructure projects improperly; nevertheless, 
they are implemented separately that causes defect in successful delivery of infrastructures" (Saghatforoush, 2014). Therefore, in order to achieve objectives of project owners and a successful and efficient delivery of infrastructure project, it is required to use such approaches. In this regard, in order to implement these approaches in projects, of course there are some barriers that disrupt the process. So, in order to overcome such barriers, it is required to suggest solutions that facilitate these approaches. Therefore, this study is to present solutions to reduce or overcome barriers in implementing constructability, operability, and maintainability concepts in infrastructure projects. Next section presents theoretical literatures for this research.

\section{Research Aim}

Construction infrastructure projects managers, for fulfilling the owners' objectives and expectations, always look for providing solutions to consider the project in the best quality and the most optimal amounts of time and money to conclusion. In this regard, the use of integrating structures, principles and concepts cause this to be more achievable. The concepts of COM are among those concepts which can significantly affect the integration process; however, in order to implement and get significant benefits from these concepts, certainly, there will be barriers on the way. Therefore to implement these concepts and achieve the project objectives faster, solutions for overcoming the barriers is highly needed. Consequently, the aim of this research is presenting solutions to overcome existing barriers in implementing the threefold concepts of COM in the infrastructure projects.

\section{Literature Review}

This section firstly explains the infrastructure Project Life Cycle and integration concept. Then, it presents the relationship between integration and the threefold concept of COM; and finally, it refers to their barriers of implementation in infrastructure projects.

\subsection{Infrastructure PLC and Integration}

The PLC is a set of successive stages of the project that are usually offered in different shapes (American Society of Civil Engineers, 1990). Project Management Institute (2008) divides PLC into four stages: The project initiation, organization and planning, execution, and project closure. Wubbenhorst (1986), introduces PLC in five phases of startup, planning, realization, operation and consumption. On the other hand, Howes and Robinson (2005), introduce phases of PLC as: 1) Planning phase, including defining project objectives, selecting an appropriate workplace, and confirming feasibility studies and planning schemes. 2) Designing phase, includes stages of accurate and schematic design and to satisfy the needs of contractors and customers. 3) Construction phase, covers all activities, equipment, material, laboratories, and available elements in workshop based on full realization of benefits of customers. 4) Post acquisition phase, includes utilizing and maintaining infrastructure properties that completes by recovering/supplying project. Also the PLC includes conceptual and feasibility studies, engineering and design, logistics, construction, startup and implementation, operation and utilization, destruction and adjustment (Barrie and Paulson, 1992). There is a common fact among all these classifications, which is that all can fit into planning, development, construction and postacquisition phases. Since successful delivery of infrastructure projects is important and critical for project managers and owners, appropriate contribution between project investors and main stakeholders involved in the PLC can be very considerable and effective on project objectives (Webster's, 1913). Therefore, creating synchronization among different phases of PLC results in its successful delivery. In this regard, according to the recent studies implemented by Saghatforoush (2014), this can be achieved through applying such concepts that are introduced to constructability, operability and maintainability. For this reason, the next section presents the concept of integration through introducing these concepts.

\subsection{Integration and Threefold Concepts}

Successful delivery of infrastructure projects is the main objective of project owners. Integration of PLC phases is an effective and useful technique of facilitating success in delivery of projects. The integration is defined as a general act or process to uniform something (Webster's, 1913). In the field of project management, this term is defined as "sharing information among project partners or modeling information resulted from separate systems" (O'Connor and Yang 2004). Project Management Institute (1996), defines integration as a process that guarantees different indexes of the desired project desirably and wellcoordinated. Kirsila et al. (2007), concluded that integration should be considered as a general thought and be used as an approach for successful operation and delivery. High efficiency and productivity needs integrated efforts and activities of the project users and developers (Tesch et al., 2009). Moreover, shares of various project stakeholders can be increased to create suitable integration processes in project operation (Voss, 2012). Martinsuo and Ahola (2010) explained a noble sample integration model, in which integration of project employers, suppliers and contractors is considered that results in easier delivery of complex projects. Cox and Thompson (1997), presented a model to extend and develop contractual relations in order to proportionate project objectives with real needs of users.

In a research, integration is defined as a method for sharing unique findings that results in developing significant structural reference framework, not settling conflicts and reaching a unified perception. The process of revealing and studying the interpretations, provides the possibility of influencing consensus background and offers the possibility of mutual interpretation that causes achieving a new definition of situation that all partners have participated in it” (Boland Jr and Tenkasi, 1995). According to a comprehensive study implemented by Trigunarsyah and Skitmore (2010), in order to achieve comprehensive, extensive and real successful delivery, integrating ideas and opinions from different phases of project are considered to: 1) achieve project overall objectives; 2) proportionate final project ideas according to project desired application; and 3) desirable and effective maintenance of project equipment and facilities to pause and delay resume and restoration and also destruction and removals. In other words, BIM and other Technologies have been investigated for facilities 
maintenance in venues including public housing, and industrial facilities (Ko, 2017). In this regard, by benefiting from constructability concept, one can realize the first case with feedback, experience and knowledge inputs of construction phase to initial phases. In accordance with the second case; the operability concept can accomplish project proportion for desired application through providing a foundation for entering investors and contractors of operation and maintenance to initial phases of the PLC; and finally, maintainability by entering contractors and stakeholders of repair and maintenance to initial stages and taking advantage of their experiences and opinions, enhances the third case. Therefore, these three concepts, introduced as three comprehensive management techniques and tools to facilitate integration processes to achieve project success faster and as easy as possible, and in order to use and benefit from them, it is required to have a better perception and knowledge about these three concepts (Saghatforoush, 2014). Recently, Arbabi et al. (2015) conducted assessment of the needs for identifying these threefold concepts in the Iranian construction industry. Since using these concepts in infrastructure projects can be accompanied with various barriers, the solutions should also be categorized for them, in the next section; the barriers for implementing these threefold concepts in infrastructure projects are shown.

\subsection{Barriers for Implementing of the Threefold Concepts of COM}

Following studies conducted on the threefold concepts of constructability, operability, and maintainability, some identified and evaluated available barriers in implementing them in infrastructure projects. These studies have looked for barriers in different fields. Most of these studies were in line with the constructability concept and some of them also focused on the operability and maintainability concepts.

These studies have been done in countries leading in the field of construction industry. But none of them involved all three concepts comprehensively. In this regard, Arbabi et al. (2016), identified and evaluated barriers of implementing the threefold concepts of COM in infrastructure projects through a systematic classification using the Meta-Synthesis method, reported barriers of implementing the threefold concepts recently. This classification is organized in 5 major groups and 12 major subgroups, which are proposed as framework of barriers for implementation of the threefold concepts. This framework is shown in the Figure 1 (also refer to Arbabi et al., 2016).

As the next step, to overcome such barriers, it is required to look for the solutions in available literature. To achieve that, the methodology adopted is presented as follows.

\section{Research methodology}

In order to identify and classify available solutions to overcome barriers for implementation of the threefold concept in infrastructure projects, the qualitative method of Meta-Synthesis has been applied. Next sub-section introduces the foundations and definitions of this method.

\subsection{The Meta-Synthesis Method}

The Meta-Synthesis method is efficient for qualitative studies in different fields of science, and has attracted attention of many researchers around the world recently. In the field of quantitative studies, there are several methods available for analyzing the data, but in the field of qualitative studies, such methods have not still reached comprehensive and suitable progresses for analyzing the research findings (Dixon - Woods, Fitzpatrick, and Roberts, 2001).

The Meta-Synthesis is a set of qualitative outcomes resulting from studies. In other words it is a more compact level of results taken from translation and combination of articles, a consensus identification, a hypothesis formulation and assessment of conflicts in available patterns of research studies that make possible theorizing at a much higher level (Zimmer, 2006). The MetaSynthesis method is applied for combining and integrating several studies to produce comprehensive findings. In fact the Meta-Synthesis method investigates desirable data and findings of previous studies qualitatively. This process, by using a systematic and coherent style, investigates and combined several studies and explains a novel analogy of the desired phenomenon (Zimmer, 2006). The MetaSynthesis can be considered as formulating a set of studies, and achieve a more general metaphor by separating and analyzing them into fundamental and reliable points and finally by combining and exchanging findings a new perception and interpretation of the investigated phenomenon is created in the form of a single study (Shirpak et al., 2010).

Since in this research, researcher aims to investigate and present available solutions to overcome barriers of implementing the threefold concepts in infrastructure projects, the Meta-Synthesis method is chosen as the most appropriate method. This method provides a strong foundation for investigation and evaluation of previous studies systematically, and extracts efficient data from selected resources and classifies them according to researcher needs.

\subsection{The Meta-Synthesis Method Implementation Process}

Noblit and Hare (1988), have proposed the MetaSynthesis method for synthesis of qualitative studies, which includes a process with seven stages of implementation. This process is presented in the Fig. 2.

In the next section, the process of implementation of qualitative data analysis based on the Meta-Synthesis method is presented. 


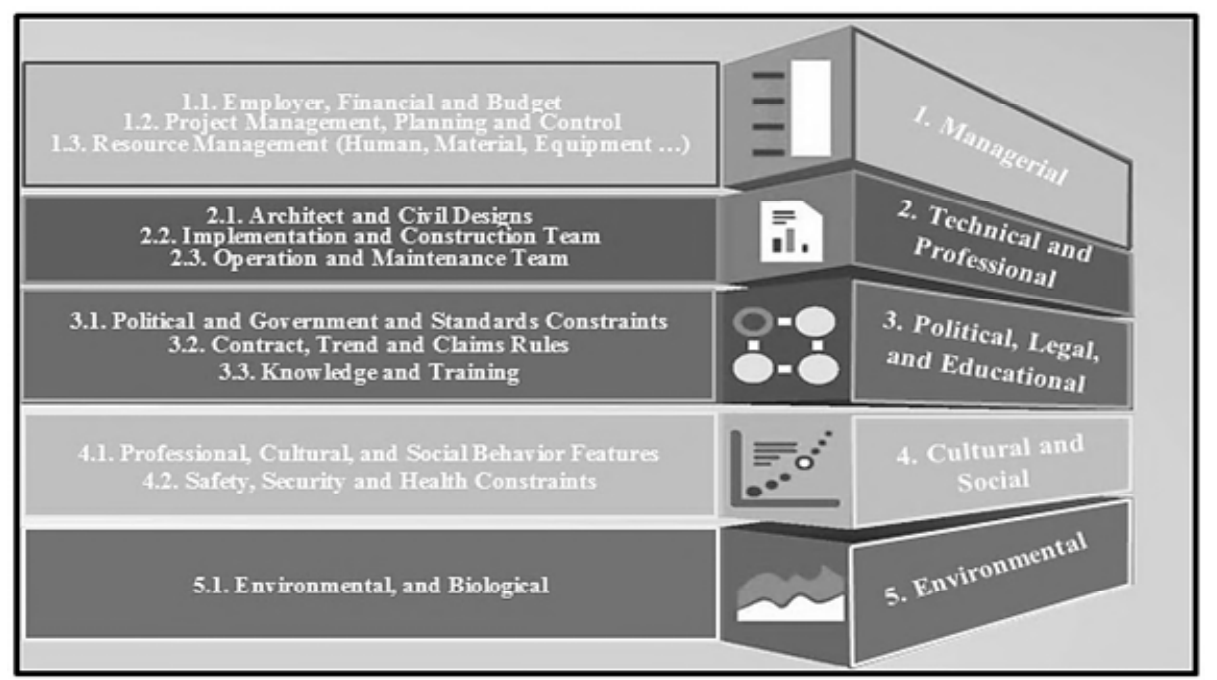

Fig. 1. Framework of the barriers for implementation threefold concepts (Arbabi et al., 2016)

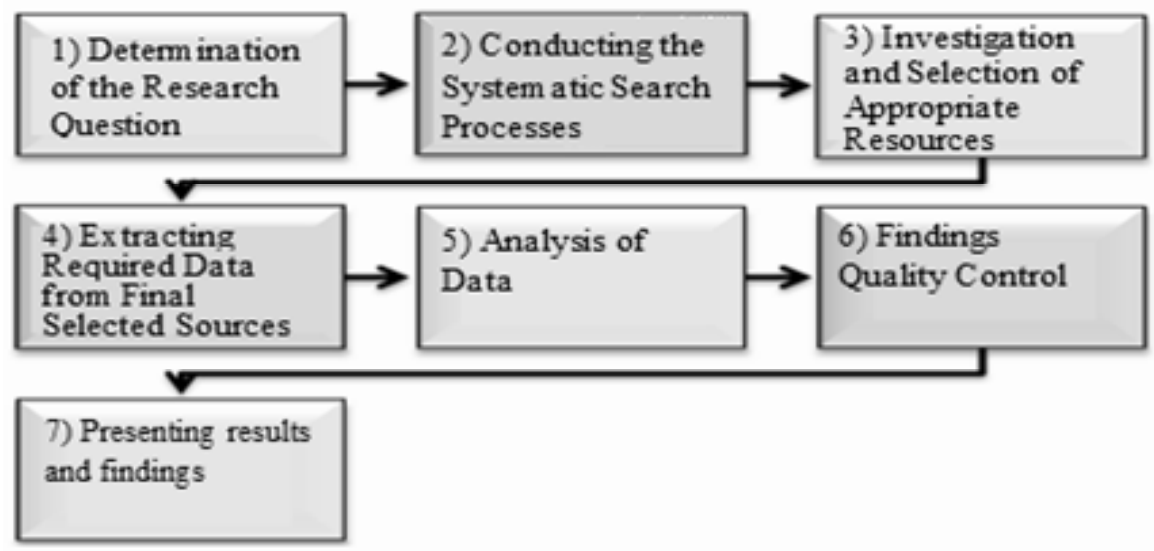

Fig. 2. Seven stages in implementation of the meta-synthesis method

\section{Data Analysis}

In this section, sevenfold stages of the Meta-Synthesis method are implemented and extended in detail. Then, collected data are summarized and classified using descriptive coding analysis. Such a coding is appropriate for those studies that have several data (Saldaña, 2015; Sandelowski and Barroso, 2006). In the second place, codes and data result from descriptive coding, were reviewed by pattern coding, and were included in a more comprehensive and overall classification of the investigated issue. Finally a comprehensive and detailed concept and content of the desired phenomenon is obtained (Zimmer, 2006). In order to facilitate this, the NVivo software has been used, which is for faster data analysis process in qualitative studies. It is also useful when amount of data is increased in the analysis phase (Zolfagharian and Latifi, 2011). Following, descriptions about implementing each stage of the meta-synthesis method are presented.

\section{Stage One: Determination of the Research Question}

Research question in the Meta-Synthesis method should be in the field of previous research studies of researcher or also adapted from interests of researcher (Beck, 2002; Beck, 2002; Paterson, 2001; Paterson, 2001; Paterson and
Thorne, 2003). In determining question for the MetaSynthesis, four factors should be specified. First, "What" of research is considered. In the present study, "What" relates to identifying and classifying initial barriers and presenting suggestions and solutions to minimize and settle them. Secondly, "Who" of research is considered, which indicates research population. In this study, reliable databases, scientific articles, M.Sc. and Ph.D. theses, and books have been used as the major databases. Thirdly, "When", which determines time period of investigated studies. In this research, conducted studies since 1970 to 2015 are considered. And finally, fourth factor is "How", which indicates the method or approach that is used for data collection phase. In the present research, literature review of documents related to research topic, which is named as document review, as well as interviews with experienced stakeholders in projects are applied. It should be noted that in the Meta-Synthesis method, content of studies is also regarded as data used as findings of studies (Noblit and Hare, 1988; Shirpak et al., 2010). Considering these explanations, the question for this research is as follows:

What are available solutions to overcome barriers for implementation of the threefold concepts and how could classify these barriers? 
Stage Two: Conducting the Systematic Search Processes

To conduct the systematic search processes, reliable databases are used as presented in the Table 2. For that, some specific keywords for searching resources are applied which are illustrated in the Table 1:

Table 1. Keywords

\begin{tabular}{|c|}
\hline Keywords \\
\hline Constructability, Operability, Maintainability \\
\hline \\
Overcome Problems \\
Overcome Barriers \\
Overcome Obstacles \\
Solutions Problems \\
Solutions Barriers \\
Solutions Obstacles \\
\hline
\end{tabular}

Table 2. Databases

\begin{tabular}{|ll|}
\hline \multicolumn{1}{|c|}{ English data bases } \\
\hline$\checkmark$ & ASCE \\
$\checkmark$ & Science Direct (Elsevier) \\
$\checkmark$ & Emerald \\
$\checkmark$ & Taylor \& Francis Online \\
$\checkmark$ & Wiley Online Library \\
$\checkmark$ & Springer \\
$\checkmark$ & Scholar. Google \\
\hline
\end{tabular}

Stage Three: Investigation and Selection of Appropriate Resources

The collected articles are investigated in several stages, which at each stage, investigating a number of these articles are excluded from the Meta-Synthesis process. On the other hand, in the Meta-Synthesis method, there are criteria to select, accept and reject articles (Najafi et al., 2013). While investigating the collected articles, the
“Critical Appraisal Skills Program” technique is used. This technique presents a list, in which ten indices are stated for qualitative evaluation of accuracy and reliability of each article. These criteria include: (1) research objectives; (2) logic and methodology; (3) research plan; (4) sampling method; (5) data collection; (6) reflectivity, which is relationship between researcher and participants; (7) ethical considerations; (8) accuracy and data analysis; (9) clear explanation of finings; and (10) research value. In order to take advantage of these criteria, each of them receives a score from one to five. For this reason, based on a 50 point scale, articles are classified. Therefore, these articles receives a score from zero to 50, and in this way, they are ranged from very poor to very good. Very good (41-50), good (31-40), medium (21-30), poor (11-20), and very poor (0-10) (Public Health Resource Unit, 2006). According to such scoring, those articles with scores less than 21 were excluded from the Meta-Synthesis process. One of the most important steps of the Meta-Synthesis is stating proper criteria for selecting articles (Weed, 2006). As presented in the Table 3 , in this study, following criteria are considered:

Table 3. Selected Criteria for the Meta-Synthesis Process

\begin{tabular}{|l|l|}
\hline \multicolumn{2}{|c|}{ Selected Criteria for the Meta-Synthesis Process } \\
\hline $\begin{array}{l}\text { Language of } \\
\text { searches: English }\end{array}$ & $\begin{array}{l}\text { Texts and findings: } \\
\text { qualitative, quantitative- } \\
\text { qualitative }\end{array}$ \\
$\begin{array}{l}\text { Publication time: } \\
\text { Time period between }\end{array}$ & $\begin{array}{l}\text { Type of study: articles, } \\
\text { thesis, published reports, } \\
\text { institutional to 2015 } \\
\text { organizational researches }\end{array}$ \\
\hline
\end{tabular}

The time criteria for publication of studies considered in this research, is based on primary definitions and explanations stated on the concept of constructability in 1970s. This process is shown in the Fig. 3 schematically.

As shown above, 32 sources are finally left which includes two reports from specialized research, two theses, one book and 27 journal or conference articles. These sources are used for the proposed qualitative analysis of this study.

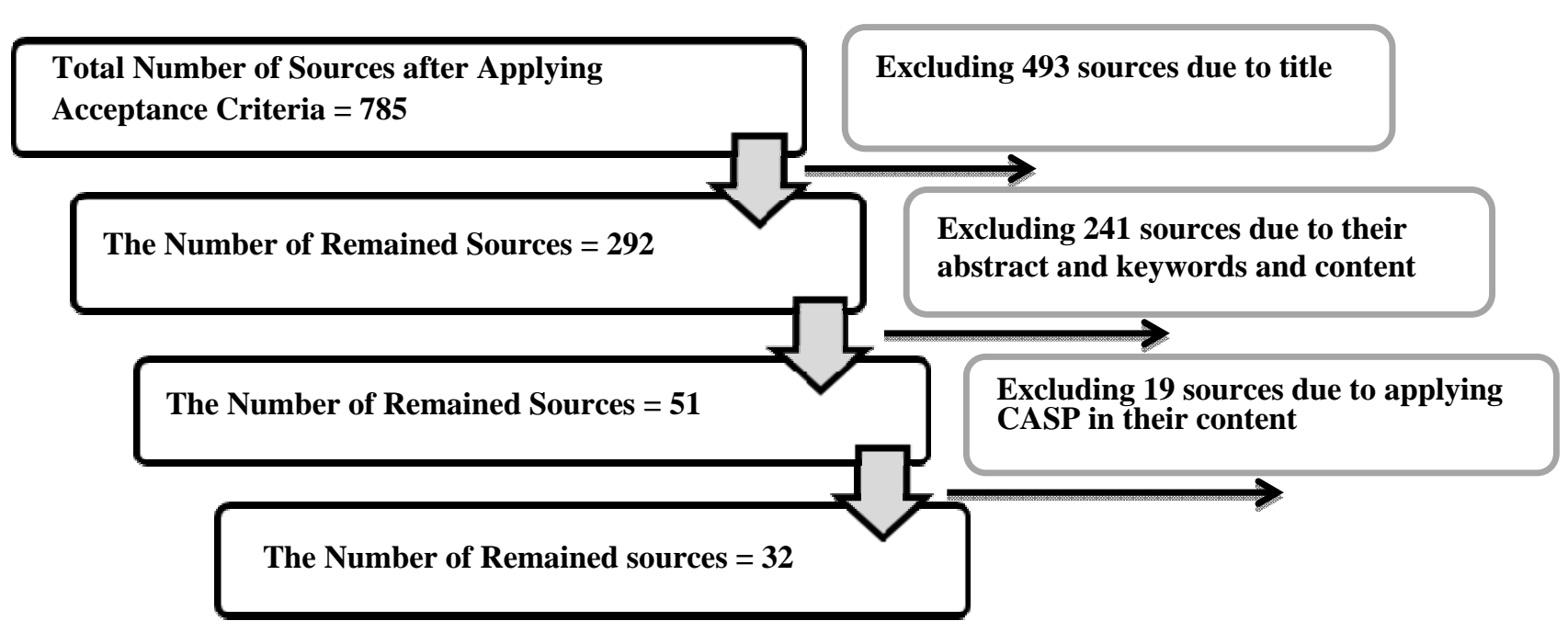

Fig. 3. The selection process to find relevant sources of solutions to overcome com barriers 


\section{Stage Four: Extracting Required Data from Final Selected Sources}

At this stage, in accordance with the defined research question and considering the needs of this study, detailed investigation was applied on each of the final selected sources. The extracted data from selected data sources were analyzed using descriptive coding processes.

\section{Stage Five: Analysis of Data}

Provided data from the previous stage combined and analyzed at this stage; besides that, they are translated and interpreted based on the Meta-Synthesis method.

Accordingly, each data with one code was classified initially using pattern coding method. Through this coding technique, codes that are closer to each other semantically and conceptually are placed in one category. Following, through utilizing coding and model analysis, each of those categories classified under a more general title extracted from the concept of the same category. It should be noted that these coding and classifications of solutions were done by aid of the NVivo software as a supportive analytical tool.

Table 4. Solutions to overcome barriers for implementation of the threefold concepts of com in the construction

\section{Stage Six: Findings Quality Control}

In this study, the researcher chose the selected articles from reliable databases, and during this process, those cases without required quality and credit, were eliminated from the Meta-Synthesis implementation process. Moreover, it is noteworthy to highlight that, in the final selection process of resources, as it is shown in the Fig. 3, the "Critical Appraisal Skill Program" (CASP) has been used that provided the possibility to ensure about quality of articles, and in a similar way, data coding and classification and selected codes from context of the final selected resources were analyzed and investigated in several stages. For this reason, these are among reasons that can fulfill the quality of data collected through the Meta-Synthesis method.

\section{Stage Seven: Presentation of Findings}

At this stage, the question highlighted in the stage one is answered. Classification of solutions to overcome barriers for implementation of the threefold concept in construction infrastructure projects is presented in the Table 4.

\section{infrastructure projects}

$\begin{array}{r}\text { 1. Project management and organization } \\ \hline 1.1 \text { Rules, standards, and knowledge }\end{array}$

\begin{tabular}{ll}
\hline \multicolumn{1}{c}{1.1 Rules, standards, and knowledge } & References \\
\hline Learning and benefiting from feedback of residents and users, Codification of \\
standards and standardizing elements in designs according to uniqueness of all (Meng, 2013; O'Connor et al., 1987; \\
projects and taking advantage of expertise of construction agents and developing \\
scientific standards.
\end{tabular}

Stating accurate specifications of material in booklets of project specifications and using standards and regulations completely and accurately, and also standardizing material, construction details, construction method and systems, etc. through repeat processes- centered results in reduction of costs. Supportive rules of designers to offer prefabrication and pre-fabricated plans and designs sensitive to optimal construction.

Identifying educational needs in personnel and effective management policies on construction resources such as improving designing responsibilities and working domains and standards of labor and education, Developing rules for taking advantage of essential computer software according to favorable economic gain, Modifying and changing employment methods; creating more emphasis on construction experience and looking for having appropriate communication and group skills.

Providing internal training for personnel and stakeholders in different and (Bröchner, 2003; Lai et al., 2010; changing situations and paradigms about construction method, constructability, Liu and Issa, 2015; Meng, 2013; field methods and difficulties and project site, lessons learned etc. training O'Connor and Miller, 1995; YY Ling sessions and seminars, with offering professional degree.

Dispatching staff to short courses of learning constructability, Increasing awareness about the need of using constructability at the beginning of the job, Periodic and on time program of asking questions from designer personnel about issues related to constructability in order to determine extent and depth of their knowledge, Developing strategy and guide for paying and improving constructability in projects, Adding constructability to curricula and educational courses of designers and engineers, Developing and presenting short courses of constructability for professional development.

Paying attention to improving knowledge of contractors for presence at initial phases and knowledge integration for codifying technical standards, Sharing knowledge to avoid construction, operation and maintenance problems, knowledge and experience development at initial phases of projects, Codification and using check lists and standards of maintenance.
(Dunston et al., 2005; O'Connor et al., 1987; O'Connor et al., 1986; Russell et al., 1994;Tatum, 2005)

(Meng, 2013; O'Connor et al., 1986; Tatum, 2005) et al., 2014)

(O'Connor and Miller, 1995; Dunston, Gambatese, and McManus, 2005; Gambatese, Pocock, and Dunston, 2007; Russell and Swiggum, 1994a)

(Saghatforoush, 2014; Saghatforoush, Trigunarsyah, and Too, 2012; Liu and Issa, 2015; Bröchner, 2003) 
Table 4. Solutions to overcome barriers for implementation of the threefold concepts of com in the construction infrastructure projects (continued)

1. Project management and organization

1.2 Financial affairs, budget, and contracts

Using contractual and investing processes and capabilities under title of public
private partnerships (PPPs), Using contractual and investing processes and capabilities under title of private finance initiative (PFI), Emphasis on PLC costs and costs' control.

Providing motivational clauses and comments in contracts.

References

(Saghatforoush, 2014; Meng, 2013;

Saghatforoush, Trigunarsyah, and

Too, 2012; YY Ling et al., 2014;

Meier and Russell, 2000)

(CII, 1993a; Gambatese, Pocock, and Dunston, 2007)

Creating an agreement for participation and cooperation as a plan between employers and contractors to focus on developing a job relationship and appropriate interaction and creating one unified project team to achieve a common mission and project objectives, which should be investigated: 1) identifying barriers for a successful communication, 2) setting objectives for project and creating an statement of common mission, 3) developing methods for solving problems, 4) consensus on project schedule tables, 5) assigning responsibilities, Developing a list of issues for pre-tender meeting, Creating project constructability agreements and contracts, in which constructability team should state its commitment for constructability and setting objectives for project.

Sooner, benefiting from inputs and experiences of builder section for doing designing works in contracts, Paying attention to referral to constructability in contract documents, Creating a commitment and continuity in contractual methods to take advantage of construction experiences at initial phases of the project.

Using life cycle cost (LCC) considers initial investment costs, future costs, predicting life of building components and effective factors on investment evaluation such as discount rate and inflation, disruption in building operations, analyzing failure and destruction, taxes and energy efficiency. Using life cycle cost (LCC) at different stages of decision making process, to help save money on construction costs.

Life cycle cost (LCC) model compares alternatives of design and selects the best suggestion of system. The effect of participation of life cycle cost (LCC) during the stage before utilization and occupation can be permanent by using performance indices of life cycle cost (LCC) during the stage after utilization. More accurate preparation of contract documents in order to presence of maintenance contractors at initial stages.

Assigning more time in tender to construction contractors for more accurate and more detailed investigating and evaluating plans in terms of accuracy of information, authenticity, coordination and conformity with executive methods, Considering the least restrictions in construction documents and contracts about cases such as access and using site, safety, facilities and temporary equipment and delivery points, as they can have significant effect on the way of doing and scheduling work by builder. Inclusion of design phase time schedule in contractual documents can be a kind of guarantee for doing job according to scheduling in the allotted time. Per-construction scheduling in contract and tender documents, for more information to avoid and reduce problems during construction, can have a lot of benefits for the owner.

Presenting investigation programs that cause improving creativity and intelligent risk-taking. Changing conventional civil budget in project schedule and design; additional investigation in design for constructability studies, using constructability as a part of a standard price suggestion and try to control and reduce prices in suggestions, presenting formal commitment to constructability idea; then convincing owners about this issue that constructability should be used in project process at the beginning of the job. Creating a short list of contractors who present constructability input data for creating opportunity in short list of price proposers. Assigning the possibility of appropriate presence at project place in design budget, for field visits by designers.

(O'Connor and Tucker, 1986; C. B. Tatum, 1987; Peterson and Dorsey, 2000; CII, 1993a; Pulaski, Horman, and Riley, 2006;Fisher, Anderson, and Rahman, 2000; C. Tatum, 2005)

(Frank, 2014; Kashiwagi, Nuno, and Moor, 1994; Chew, Tan, and Kang, 2004)

(Frank, 2014; Kashiwagi, Nuno, and Moor, 1994; Chew, Tan, and Kang, 2004; Assaf, Al-Hammad, and Al-Shihah, 1996)

(Glavinich, 1995)

(O'Connor and Miller, 1995; Dunston, Gambatese, and McManus, 2005; Gambatese, Pocock, and Dunston, 2007; Russell and Swiggum, 1994a) 
Table 4. Solutions to overcome barriers for implementation of the threefold concepts of com in the construction infrastructure projects (continued)

\begin{tabular}{cc}
\hline 1.3 Owner and client, project management and project planning and control \\
team
\end{tabular}

Better construction through conducting constructability, will be caused from committed interest of main factors and a focused effort toward settling barriers and encouraging team work. Selecting design sub-consultant and construction consultant, who are appointed by client and project management, jointly, and help method of doing and planning project specifically. Investigating restrictions and barriers that may be effective in construction stage and make pauses in it, and are specified and determined at planning and conceptual design stage.

Suitability of participation of facilities and equipment management at initial stages of the project, Investigating and evaluating design of operability, maintainability, and serviceability items by management, Identifying and selecting strategies of operation and repair and maintenance and optimal replacement for them by management, Communicate with construction and design teams for selecting cost effective design option which will optimize lifetime costs and emphasizing increase of lifetime costs, Acknowledging advantages of facilities management participation at initial phases of the project and more attention to the role of facilities management, Architects and engineers and facilities management should learn from each other and should know that how they can have an adequate job interaction, communication and conversation.

Codifying design activities programs and scheduling, provision and supply based on construction needs and updating design schedule for identifying and modifying construction problems.

Identifying work processes' features that are effective at the time of considering constructability, Identifying economic effects of advantages and efforts of constructability, Evaluating internal relations between constructability and other features of PLC such as operability and maintainability, Determining constructability effects on cost, scheduling, quality and safety of PLC, Creating a database of constructability lessons learned, Research and developing new constructability tools, Codifying policy statement and constructability aim. Using control tool for planning and scheduling like critical path method, which is an important tool for formulating constructability investigation process. Holding meeting between contractors and employer to determine a list of problems and issues related to pre-construction as a clarification channel for constructability feedbacks.

Presenting agenda for meetings and constructability team, Take advantage of operation and maintenance check list, Creating an organizational structure for constructability, Creating and applying form of suggesting constructability ideas, Implementing responsibility matrix for determining responsibility of each of factors and also taking advantage of lessons learned for documentation. Statement and declaration of project organization objectives of investigating constructability implementation, Determining and showing management and company commitment level for investigating and implementing constructability, Identifying executive sponsor of company for investigating and implementing constructability, Determining relations and connectors for implementing constructability at project level.

Project owners should have an effective role in constructability of design programs and scheduling and logistic, working domain and range and related data to project place, they should investigate and agree with study programs and undertake construction and leading project team with a productivity sense and strong financial influence. Creating a check list for post construction investigations and using them at the end of work to start constructability (O'Connor and Tucker, 1986; Glavinich, 1995)

(Meng, 2013; Bröchner, 2003; Meier and Russell, 2000)

(Griffith and Sidwell, 1997)

(Gambatese, Pocock, and Dunston, 2007)

(CII, 1993a; Gambatese, Pocock, and Dunston, 2007; Russell and Swiggum, 1994a; Russell and Swiggum, 1994b; Fisher, Anderson, and Rahman, 2000)

(O'Connor, Rusch, and Schulz, 1987; C. B. Tatum, 1987; Gambatese, Pocock, and Dunston, 2007; Russell and Swiggum, 1994a; C. Tatum, 2005) 
Table 4. Solutions to overcome barriers for implementation of the threefold concepts of com in the construction infrastructure projects (continued)

References

\begin{abstract}
1. Project management and organization
1.3 Owner and client, project management and project planning and control team

Project organization and executive programs available to experienced personnel in construction should be investigated continuously, so that they can help designer group and expecting active participation of these people. Scheduling development process should be done with presence of experts of different fields with sufficient experience in the field of construction. Searching methods to deal with and minimize project influencability by conditions change, by accurate investigations through using modern technologies by designers and contractors interaction. Contractor input data should be used in identifying material and methods. One should challenge previous executive processes, should welcome presenting creativity, should support new ideas, and should publish successes. One should support existence of intra organizational communications and plan for them especially among designers and contractors. Project group always should consider an important point: reducing investment costs Focus on project optimization instead of design phase optimization. A lot of efforts should be done in order to organizing profile book for a certain project.
\end{abstract}

Most of engineering problems are solved relatively, but solutions should be in a general form. Also, taking one effective step will be required that is integrating different sections, and paying special attention to project implementation based on integration in design and construction process and effort to introduce its advantages.

Managers should emphasize on using experienced construction personnel at the beginning of project. Using construction conditions at the beginning of the project, creating a balance method and recognizing project schedule problems can result in changes in design concepts, regulations or the method of avoiding these problems. Considering and using project objectives and clear presentation as a criterion for making main decisions of the project by owner and employer. Using constructability at initial phases is one the most important methods for managers who are looking for better solutions to achieve their own and project's objectives. Owners present constructability as a main point, concern and need in the project and demand them at the beginning of the project. Employer should emphasize on using modern methods in design and modern technologies of construction. Using constructability as a competition basis in design and contractor firms by managers. Managers should put high priority on creating pre-construction schedule.

Feedback/ lessons learned from systems (computer systems and educational workshops) to the objective, presenting purposeful information for avoiding errors and documenting lessons learned. Creating basic modifications in working domain of subcontractors and improved assignment of responsibilities by project management. Creating an effective relation for exchanging engineering information and information access. Comprehensive system or project designed to extract innovative ideas and potential improvement of all involved workers in the job. Often for creating motivation, a reward system is used. Constructability project team: a team of related professional people, presents design constructability by purposeful investigation and analysis, and in a sense, creating and founding organization and applied supportive methods, collecting key members of owner team. Sponsor of constructability and coordinator of project: a person at professional level (design consultant) who supports project constructability benefits during design, logistics and construction. Leading and holding continuous meetings and awareness of seminars at all levels. Setting objectives for constructability effort and developing constructability methods and integrating with project activities.
(O'Connor, Rusch, and Schulz, 1987; O'Connor and Miller, 1995; Dunston, Gambatese, and McManus, 2005; Gambatese, Pocock, and Dunston, 2007; Kala, Seppänen, and Stein, 2010; Russell and Swiggum, 1994b)

(O'Connor, Rusch, and Schulz, 1987; Meng, 2013; James T , O'Connor, and Yang, 2004; YY Ling, GY Toh, Kumaraswamy, and Wong, 2014; Meier and Russell, 2000; C. B. Tatum, 1987; Chew, Tan, and Kang, 2004; C. Tatum, 2005)

(C. Tatum, 2005; C. B. Tatum, 1987)

(James T O'Connor and Tucker, 1986; James T O'Connor and Miller, 1995; C. B. Tatum, 1987; Peterson and Dorsey, 2000; CII, 1993a; Pulaski, Horman, and Riley, 2006; Arditi, Elhassan, and Toklu, 2004; Fisher, Anderson, and Rahman, 2000; C. Tatum, 2005) 
Table 4. Solutions to overcome barriers for implementation of the threefold concepts of com in the construction infrastructure projects (continued)

\begin{tabular}{cc}
\hline 1.3 Owner and client, project management and project planning and control \\
team
\end{tabular}

Brainstorming sessions: project team gathers to plan next steps or develop and evaluate solutions for specific aspects of project. Usually it is a focused event. Discussion with contractors, customers and suppliers: focused discussion sessions with experts about possible strategies and the best strategies in order to solve key technical issues related to project and design. QC/QA after each design stage: management system for systematic evaluation of design after each phase. Designed for "creating" quality in project and also is employed in construction starting up and management. Considering "performance-based technical specifications system” to help the owner in considering design options to achieve repair and maintenance objectives.

In order to investigate developed relationship during design, construction and among user needs to confirm completed building performance, a chain of quality and evaluation system (customers, designers, contractors, manufactures and experts/ offering repair and maintenance) should be provided at site. Taking advantage of building appraisal quality (BAQ) method with 9 criteria: (1) introduction, (2) space, (3) access and circulation, (4) business services, (5) personnel accommodations, (6) workplace, (7) health and safety, (8) structural considerations, (9) manageability. With complete consistence with this evaluation, least repair and maintenance of building is expected. Reviewing whole building performance, determining criteria and quality management methods should be considered in leading changes toward improved maintainability.

Material, methods and equipment, which are not usually used in project place and site, should be identified by designers and experience of constructor team, and should avoid their usage to prevent increasing project costs or delay. A specific area with a lot of unskilled labor, with low mechanization, may need a design that considers intensive construction process. Considering and identifying local traditions, which may include observing special holiday periods, can have significant effect on project costs and scheduling. Details and time schedule form should always be dictated by project objective, and also project scope and complexity. It is required that any effort of pre-construction scheduling, not only includes observing their planned activities and time periods, but also it is composed of required equipment and material provision. Project team can enjoy expertise of a construction manager (CM) during initial phases of design to create a pre-construction schedule.

Determining and specifying a powerful supportive program by manager and planning team up to the highest possible level, Regular report of advantages of constructability program, Creating constructability by the responsibility of younger and more active personnel who are more involved in the present situation. Investigating and screening personnel and people who support present situation, regularly. Establishing relationship about construction issues from local and field engineers with official engineers and designers. Correction and change of management practices of design to enhance the possibility of observing issues and consequences of constructability such as presenting them in agenda of regular meetings.

Creating success documents of this method and using them for selling program to owners; economically defensible data to prove advantages of effort at initial staged of the project and dealing with this mindset that this method is uneconomic. Extending this view that constructability should be viewed as an investment opportunity by reducing corresponding costs. Using only designers and engineers with effective and powerful constructability capabilities. Keep team members focused on common objectives and accepted processes instead of (Pulaski, Horman, and Riley, 2006; Kashiwagi, Nuno, and Moor, 1994; Chew, Tan, and Kang, 2004; Arditi, Elhassan, and Toklu, 2004)

(Chew, Tan, and Kang, 2004)

(Glavinich, 1995)

(James T O'Connor and Miller, 1995; Dunston, Gambatese, and McManus, 2005; Gambatese, Pocock, and Dunston, 2007; Russell and Swiggum, 1994a; Kala, Seppänen, and Stein, 2010)

(James $\mathrm{T}$ O'Connor and Yang, 2004; James T O'Connor and Miller, 1995; Kala, Seppänen, and Stein, 2010; Russell and Swiggum, 1994b; Fisher, Anderson, and Rahman, 2000; C. Tatum, 2005) personal issues. 
Table 4. Solutions to overcome barriers for implementation of the threefold concepts of com in the construction infrastructure projects (continued)

\begin{tabular}{|c|c|}
\hline \multicolumn{2}{|l|}{ 1. Project management and organization } \\
\hline $\begin{array}{l}\begin{array}{l}1.3 \text { Owner and client, project management and project planning and control } \\
\text { team }\end{array} \\
\text {. }\end{array}$ & References \\
\hline $\begin{array}{l}\text { Changing attitudes; attracting designers to observing and investigating project } \\
\text { place as a suitable information source. Using foreign experts for doing and } \\
\text { conducting perfect evaluation: Is constructability issue has been investigated } \\
\text { completely? Recognizing and perceiving this issue that value engineering by } \\
\text { itself doesn't result in perfect investigation of constructability issues extent. } \\
\text { Creating and promoting effective building teams among project personnel. } \\
\text { Consolidating presence and using a building contractor in design company. } \\
\text { Using constructability as an initial activity in an official activity flow program } \\
\text { of roadmap. Automatizing databases of lessons learned to provide access to } \\
\text { them at any time. }\end{array}$ & $\begin{array}{l}\text { (James T O'Connor and Miller, } \\
\text { 1995) }\end{array}$ \\
\hline $\begin{array}{l}\text { Encouraging people to share information, Regular control and supervision on } \\
\text { delivering project efficiently. Correct management of communications and } \\
\text { coordinator teams among various phases of the project by using communicative } \\
\text { tools. Worthy selection of maintenance experts for presence at initial phases. } \\
\text { Benefiting and using Building Information Modeling (BIM) to improve } \\
\text { constructability implementation. }\end{array}$ & $\begin{array}{l}\text { (Saghatforoush, 2014; Meng, 2013; } \\
\text { Saghatforoush, Trigunarsyah, and } \\
\text { Too, 2012; Liu and Issa, 2015; YY } \\
\text { Ling, GY Toh, Kumaraswamy, and } \\
\text { Wong, 2014; Dunston and } \\
\text { Williamson, 1999; Al-Hammad, } \\
\text { Assaf, and Al-Shihah, 1997) }\end{array}$ \\
\hline \multicolumn{2}{|l|}{ 2. Engineering, technical and executive } \\
\hline 2-1 Architectural and civil design engineers & References \\
\hline $\begin{array}{l}\text { Conducting continuous self-assessment in design process, It should be } \\
\text { emphasized in design practices based on integration processes. Using three, } \\
\text { four, and five dimension models in designs to improve constructability } \\
\text { implementation. Taking advantage of multimedia systems and virtual reality in } \\
\text { designs. Using the idea of registering lessons learned to improve designs. }\end{array}$ & $\begin{array}{l}\text { (Meng, 2013;CII, 1993a; } \\
\text { Gambatese, Pocock, and Dunston, } \\
\text { 2007; Kala, Seppänen, and Stein, } \\
\text { 2010) }\end{array}$ \\
\hline $\begin{array}{l}\text { Designs should be configured by construction phase to create an effective and simplified } \\
\text { communicative process. Using minimum number of elements for simpler construction in } \\
\text { designs. Using available material in conventional sizes and shapes and available in } \\
\text { designs. Using simple executive connections with minimum requirements for skilled } \\
\text { labor and control of environmental requirements in designs. Presenting designs in } \\
\text { accordance with project place conditions such as climate conditions, to justify project } \\
\text { dimensions. }\end{array}$ & $\begin{array}{l}\text { (James T O'Connor, Rusch, and Schulz, } \\
\text { 1987) }\end{array}$ \\
\hline $\begin{array}{l}\text { Using designs that cause minimizing construction dependencies, Modularization and pre- } \\
\text { assembling should be considered as a basic strategy of the project and regarded during } \\
\text { conceptual design phase. After determining modularization and initial construction } \\
\text { efforts, engineering efforts should result in support of design. And unit/ construction } \\
\text { designs should be configured such that cause ease of their construction, transfer and } \\
\text { installation. Enjoying and utilizing concept of labor availability, material, local } \\
\text { conditions and construction practices in initial designs and accurate design with view of } \\
\text { expert personnel in construction. Some of initial costs can cause significant saving in } \\
\text { future. Additional efforts of engineering cause reduction of operation at place. Also } \\
\text { special and extended studies about important issues will be helpful. }\end{array}$ & $\begin{array}{l}\text { (James T O'Connor, Rusch, and Schulz, } \\
\text { 1987; Glavinich, 1995; Gambatese, } \\
\text { Pocock, and Dunston, 2007) }\end{array}$ \\
\hline $\begin{array}{l}\text { Designers should be eager and able to interact and communicate effectively with } \\
\text { construction group. Designers should play the main role in creating a bilateral and } \\
\text { mutual space with construction domain, Designers should consider search of } \\
\text { construction priorities and informing construction group about design time tables and } \\
\text { required schedule for specific cases. Creating manufacturable and economic design and } \\
\text { presenting technical support to management and construction group. }\end{array}$ & (C. B. Tatum, 1987; C. Tatum, 2005) \\
\hline
\end{tabular}


Table 4. Solutions to overcome barriers for implementation of the threefold concepts of com in the construction infrastructure projects (continued)

2. Engineering, technical and executive

2-1 Architectural and civil design engineers $\quad$ References

Identifying complex details and simplifying design elements for construction stage by designers and by the help of experience of construction agents. Identifying needs about changes and capabilities to comply with project place and special attention to flexibility and versatility.
Specialized and detailed investigations: a group of multidiscipline experts, which are a part of project team or outside of the project who have studied the design and present feedback and criticisms. Investigating design check list: check list provides a list of key features and requirements that should be estimated and supplied before design progress and in order to evaluate cases related to appropriate accessibility, which often is a simple type of systematic Q/A method.

Computer models: in order to evaluate design features, aesthetics/ appearance, sequence options of construction and installation, designs are drafted as CAD models. Its advantage is in this issue that can create changes easily and identifying possible physical interferences and simulating different aspects of the project are studied over time. Increasing flexibility in design services and design investment levels. Creating new internal post in design organizations and company; constructability expert. Creating a database of constructability lessons learned in design companies.
(C. Tatum, 2005; James T O'Connor and Tucker, 1986)

(James T O'Connor and Yang, 2004; James T O'Connor, Rusch, and Schulz, 1987; Meng, 2013;Bröchner, 2003; Pulaski, Horman, and Riley, 2006; Arditi, Elhassan, and Toklu, 2004; Gambatese, Pocock, and Dunston, 2007; Russell and Swiggum, 1994b; Fisher, Anderson, and Rahman, 2000; C. Tatum, 2005)

(James T O'Connor and Yang, 2004; James T O'Connor, Rusch, and Schulz, 1987; James T O'Connor and Tucker, 1986; James T O'Connor and Miller, 1995;Liu and Issa, 2015; YY Ling, GY Toh, Kumaraswamy, and Wong, 2014; Pulaski, Horman, and Riley, 2006; Arditi, Elhassan, and Toklu, 2004; Dunston and Williamson, 1999; Gambatese, Pocock, and Dunston, 2007; Kala, Seppänen, and Stein, 2010; C. Tatum, 2005)

\footnotetext{
Architect designers and engineers should study constructive demands based on available conflicts and defects in designs, fairly and impartially, and tries to minimize them. Inherent activities in a special design, which result in inevitable delays and postpones, should be identified and excluded from plans and programs. Using developed exotic technologies; such that a tested and more familiar technology will realize design requirement; should be identified and excluded from plans and programs. Construction issues and problems can be corrected relatively easily and economically in design phase and with minimum effect on project total schedule. Architect/engineer should do an independent detailed investigation of technical features and plots, by the aim of removing and reducing errors and conflicts, and also recognizing any conflict inside or among plans and technical features before their final issuance. Forming an internal investigation team at the beginning of the project to study conducted designs. The aim of design investigation team will be investigating philosophy of main design in relation to design criteria, and also project constructability during design process. Design investigation team should be completely independent of design team. This team should be equipped with design senior personnel from related fields, and also on site architects and engineers. The ideal situation is that when assigned on site personnel to a project present in office, investigation meetings should be planned. Thus, on site personnel can investigate the design for constructability and also before beginning construction, obtain better perception of the aim of design. This issue results in promoting a better work relationship among office personnel and on site personnel, and also causes that on site personnel have less dependency on design team during construction.

Architect/engineer should communicate with people and sections of construction and execution to ensure all coordination and conflict settlements. Architect/engineer should consider local conditions and construction practices, and also availability of labor, (C. B. Tatum, 1987; Glavinich, 1995;

C. Tatum, 2005) material, and equipment in design.

(Glavinich, 1995)
} 
Table 4. Solutions toovercome barriers for implementation of the threefold concepts of com in the construction infrastructure projects (continued)

2. Engineering, technical and executive

2-2 Contractors: construction team and operation and maintenance team

Selected contractor allows project management team to investigate the suggestion, during which identified above costs factors and opportunity for saving costs is created. During this process, a wide range of design and construction alternatives will be suggested, which result in subsequent cost effective changes. Required measures and suggestions to remove restrictions, barriers, and for suitable constructability by team contractors in methods and operation hierarchy.
Plans should be studied by expert personnel in the field of construction. Creating schedule and determined by contractors. Receptivity and having perception about constructability evaluations at the end of the project by manufacturers. Initial constructability input data of the project should be presented by contractors. Pay special attention to safety considerations in the field of construction and project executive phase.

Contractors, during planning phase and conceptual design, should be sensitive to phase and conceptual design, should be expert in determining resource availability. Contractors, during planning phase and conceptual design, should be active in developing project implementation program and introducing and advising a study and increase of degree of engineering activities. The role of construction phase factors in initial design, focused on cost estimation and project schedule is significantly important. The role of contractor in creating constructability includes active and professional interaction with design. The role of contractor in creating constructability includes serious planning in the field of construction to create a basis for design and preparation for construction. The role of contractor in creating constructability includes using an experienced group in the field of construction.

Experimental models (physical models): Important or inseparable parts of proposal are constructed as sample and are analyzed in terms of compatibilities and improvement. inhibiting factors in projects on site and local conditions. Contractors, during planning program. Input data from construction phase factors can improve project total programs

(Griffith and Sidwell, 1997;

Kala, Seppänen, and Stein, 2010;

Russell and Swiggum, 1994b; C.

Tatum, 2005; Fisher, Anderson, and Rahman, 2000)

(Saghatforoush, 2014; James T O'Connor, Rusch, and Schulz, 1987; Saghatforoush, Trigunarsyah, and Too, 2012; James T O'Connor and Tucker, 1986; James T O'Connor and Miller, 1995; Dunston, Gambatese, and McManus, 2005; Gambatese, Pocock, and Dunston, 2007; C. Tatum, 2005)

(C. B. Tatum, 1987; C. Tatum, 2005)

(Pulaski, Horman, and Riley, 2006;

Arditi, Elhassan, and Toklu, 2004; Gambatese, Pocock, and Dunston, 2007)

Considering and investigating local conditions, especially in specific projects, maybe in which there are sources available for construction, different from available sources for a normal project, is very important. Specifications of equipment and special or custom material, in which design requirements can be supplied by using ready to use standard goods by subtle design changes, should be identified and removed from programs and plans. Specifications of material, equipment, and obsolete construction methods, should be identified and removed from programs and plans.

\subsection{Discussion}

As mentioned previously, this study is to investigate and define available solutions to overcome barriers for implementation of the threefold concepts of COM in the construction infrastructure projects. The proposed solutions by this study are classified into 2 groups and 5 subgroups. Each of these solutions has emphasis on a particular feature. For instance, dispatching employees to short term courses of learning the constructability concept or holding training sessions; this solution is among responsibilities of project organization management. As having such approaches and thoughts in project organization can promise to reach those project goals, and in this way, projects' evolution and implementation path will be in conformity with scientific developments. Also, it is employer who should emphasize on using modern methods in modern designs and technologies of construction, and in this way, show that his/her project's success as the most important items to each participating agent. As it is clear, this solution relates to employer and owner of projects and in this regard, there are other solutions referred to them in the Table 4 . Also stated that in order to implement the threefold concepts in construction infrastructure projects, there are barriers that interrupt this process. After presenting solutions, it was required to reduce these barriers, partially, and by implementing and benefiting from the threefold concept, we were one step closer to reach the main objectives of the project, and mark a successful delivery of projects. For instance, barriers stated in the Fig. 1 classification, under the title "project organization and management", can be reduced by solutions stated in the Table 4 under the title "project organization and management", and overcome some of them. It should be noted that of course suggested solutions don't involve all barriers and are not able to remove all of them, and there are some barriers that may be have no solution.

\section{Conclusion}

By applying threefold concepts discussed in Section 5.1 and the proposed solutions, the final cost and time of project can be controlled at an optimum mode. Summary of the classified solutions, under the framework of 
solutions to overcome barriers for implementation of the threefold concepts in construction infrastructure projects, is presented in the Fig. 4.

In this study, a systematic classification of the solutions to overcome barriers of implementing the threefold concepts of COM in infrastructure projects is presented. This classification has two sections: 1. Organizational, and Project Managerial 2. Engineering, Technical and Administrative, Which each contains subdivisions including: 1.1 Rules, Standards, Training and Knowledge, 1.2 Financial Affairs, Budget and Contracts, 1.3 Owner and Employer, Project Management and Planning Team and Project Control and 2.1 Civil and Architectural Design Engineers 2.2 Contractors; Construction and Operation and Maintenance Team. In summary, contributions of this research to academics and practitioners are as follows:

\section{Contribution to Academic Field}

- Use of academic and scientific concepts to advance the science of construction management and management training in specialized centers.

- This integrated and comprehensive research can reduce or overcome the barriers to implementing the threefold concepts of COM so that they can create awareness toward those involved in the projects to provide a context for future research.

\section{Contribution to Practice}

- Benefit taken from the solutions presented in this study can be applied within the consulting firms. to provide optimal design and high functionality to make a significant distinction for consultant companies.

- COM contractor companies can also benefit from the solutions provided, and it's implementing projects to improve working conditions and where the majority of components and systems implementation before the construction phase are considered and it is planned to run a quality and safe to strive.

In the future to develop and advance the threefold concepts of COM, the upcoming research by the authors targets case study implementation in the Iranian infrastructure projects focusing on healthcare projects as follows:

- Identify barriers of implementing of the threefold concepts of COM in infrastructure projects such as the case of hospital projects.

- Provide approaches for overcoming barriers of implementing of the threefold concepts of COM in infrastructure projects such as the case of hospital projects.

- Creating a framework or roadmap tailored to the needs of the construction industry in order to facilitate implementation of the threefold concepts of COM in infrastructure projects.

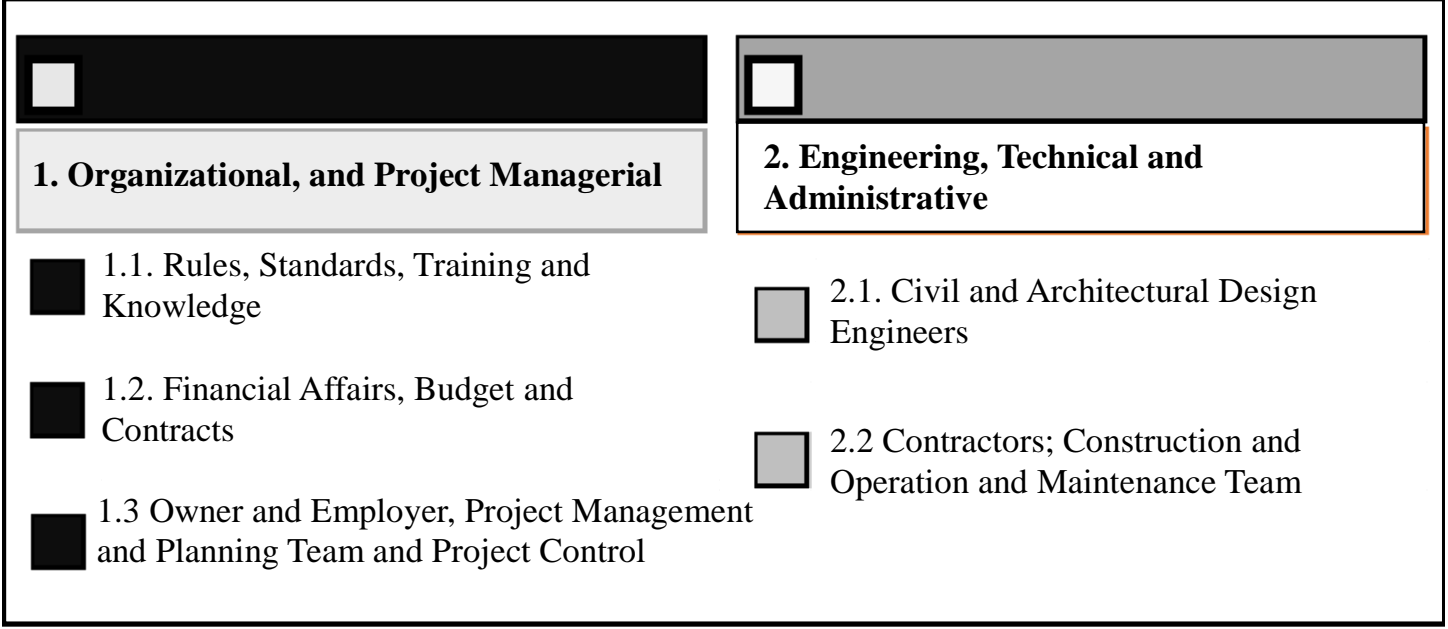

Fig. 4. Solutions to overcome barriers for implementation of the threefold concepts in construction infrastructure Projects

\section{References}

Al-Hammad, A., Assaf, S., and Al-Shihah, M. (1997). The effect of faulty design on building maintenance. Journal of Quality in Maintenance Engineering, 3(1), 29-39.

Alshawi, M., and Faraj, I. (2002). Integrated construction environments: technology and implementation. Construction Innovation, 2(1), 33-51.

Arbabi, O., Saghatforoush, E., and Athari Nikouravan, H. R. (2015). Assessment of the need for Constructability, Operability and Maintainability implementation within the Iranian construction industry. 3rd International Congress on Civil Engineering, Architecture and Urban Development, Shahid Beheshti University, Tehran-Iran.
Arbabi, O., Saghatforoush, E., and Athari Nikouravan, H. R., Mahoud, M. (2016). Identification and exploration of the barriers for constructability, operability and maintainability implementation in the infrastructure projects using meta-synthesis method. Conference on New Researches in Sciences and Engineering, 1 and 2 June 2016, Allameh Rafiei Institute of Higher Education, Qazvin - Iran.

Arditi, D., Elhassan, A., and Toklu, Y. C. (2004). Closure to "Constructability Analysis in the Design Firm" by David Arditi, Ahmed Elhassan, and Y. Cengiz Toklu. Journal of construction engineering and management, 130(2), 302-304.

American Society of Civil Engineers. (1990). Quality in the Constructed Project: a Guide for Owners, 
Designers and Constructors.

Assaf, S., Al-Hammad, A-M., and Al-Shihah, M. (1996). Effects of faulty design and construction on building maintenance. Journal of performance of constructed Facilities, 10(4), 171-174.

Barrie, D. S., and Paulson, B. C. (1992). Professional construction management: including CM, designconstruct, and general contracting, McGraw-Hill Science/Engineering/Math.

Beck, C. T. (2002). A meta-synthesis of qualitative research. MCN: The American Journal of Maternal/Child Nursing, 27(4), 214-221.

Beck, C. T. (2002). Postpartum depression: A metasynthesis. Qualitative Health Research, 12(4), 453-472.

Boland Jr, R. J., and Tenkasi, R. V. (1995). Perspective making and perspective taking in communities of knowing. Organization science, 6(4), 350-372.

Bröchner, J. (2003). Integrated development of facilities design and services. Journal of performance of constructed facilities, 17(1), 19-23.

Chew, M., Tan, S., and Kang, K. (2004). Building maintainability-Review of state of the art. Journal of Architectural Engineering, 10(3), 80-87.

Cox, A., and Thompson, I. (1997). 'Fit for purpose'contractual relations: determining a theoretical framework for construction projects. European journal of purchasing \& supply management, 3(3), 127-135.

Construction Industry Institute (CII). (1993a). "Constructability implementation guide." CII Publication 34-1, Austin, Tex.

Dictionary, O. E. (2009). Web.

Dixon-Woods, M., Fitzpatrick, R., and Roberts, K. (2001). Including qualitative research in systematic reviews: opportunities and problems. Journal of evaluation in clinical practice, 7(2), 125-133.

Dunston, P. S., Gambatese, J. A., and McManus, J. F. (2005). Assessing state transportation agency constructability implementation. Journal of construction engineering and management, 131(5), 569-578.

Dunston, P. S., and Williamson, C. E. (1999). Incorporating maintainability in constructability review process. Journal of Management in Engineering, 15(5), 56-60.

Fisher, D. J., Anderson, S. D., and Rahman, S. P. (2000). Integrating constructability tools into constructability review process. Journal of Construction Engineering and Management, 126(2), 89-96.

Frank, O. L. (2014). Exploring a best practice approach to operability and maintainability of low carbon buildings in the UK. University of Nottingham.

Gambatese, J. A., Pocock, J. B., and Dunston, P. S. (2007). Constructability concepts and practice.

Glavinich, T. E. (1995). Improving constructability during design phase. Journal of Architectural Engineering, 1(2), 73-76.

Griffith, A., and Sidwell, A. (1997). Development of constructability concepts, principles and practices. Engineering, Construction and Architectural Management, 4(4), 295-310.

Guide, P. (2004). A guide to the project management body of knowledge. Paper presented at the Project Management Institute.

Howes, R., and Robinson, H. (2005). Infrastructure for the built environment: global procurement strategies,
Routledge.

Kala, T., Seppänen, O., and Stein, C. (2010). Using an integrated 5D \& location-based planning system in a large hospital construction project. Lean Construction Journal, 2010, 102-112.

Kashiwagi, D. T., Nuno, J. P., and Moor, W. C. (1994). Optimizing facility maintenance using fuzzy logic and the management of information. Paper presented at the Proc., 16th Int. Conf. on Computational and Industrial Engineering.

Kirsilä, J., Hellström, M., and Wikström, K. (2007). Integration as a project management concept: A study of the commissioning process in industrial deliveries. International Journal of Project Management, 25(7), 714-721.

Ko, CH, (2017). Accessibility of Radio Frequency Identification Technology in Facilities Maintenance. Journal of Engineering, Project, and Production Management, 7(1), 45-53.

Lai, A. W. and Pang, P. S. (2010). Measuring performance for building maintenance providers. Journal of construction engineering and management, 136(8), 864-876.

Lennard, D., Crane, A., Beaton, I., Burton, R., Evans, D., and Gould, I. (2002). Integrating the team; dream or reality. Liverpool Best Practice Club/Rethinking Construction North West, Liverpool.

Liu, R. and Issa, R. R. (2015). Survey: Common knowledge in BIM for facility maintenance. Journal of Performance of Constructed Facilities, 30(3), 04015033

Martinsuo, M. and Ahola, T. (2010). Supplier integration in complex delivery projects: Comparison between different buyer-supplier relationships. International Journal of Project Management, 28(2), 107-116.

Meier, J. R. and Russell, J. S. (2000). Model process for implementing maintainability. Journal of Construction Engineering and Management, 126(6), 440-450.

Meng, X. (2013). Involvement of facilities management specialists in building design: United Kingdom experience. Journal of Performance of Constructed Facilities, 27(5), 500-507.

Najafi, F., Monjazebi, F., and Nikpeyma, N. (2013). Meta-Synthesis of qualitative research in nursing: a review. Journal of Qualitative Research in Health Sciences, 2(4), 320-335.

Noblit, G. W. and Hare, R. D. (1988). Meta-ethnography: Synthesizing qualitative studies (Vol. 11), sage.

O'Connor, J. T. and Miller, S. J. (1995). Overcoming barriers to successful constructability implementation efforts. Journal of performance of constructed facilities, 9(2), 117-128.

O'Connor, J. T., Rusch, S. E., and Schulz, M. J. (1987). Constructability concepts for engineering and procurement. Journal of Construction Engineering and Management, 113(2), 235-248.

O'Connor, J. T. and Tucker, R. L. (1986). Industrial project constructability improvement. Journal of Construction Engineering and Management, 112(1), 69-82.

O'Connor, J. T. and Yang, L. R. (2004). Impact of integration and automation technology on project success measures Towards a Vision for Information Technology in Civil Engineering, 1-12.

Paterson, B. L. (2001). Meta-study of qualitative health research: A practical guide to meta-analysis and 
78 Arbabi, O., Saghatforoush, E., Nikouravan, H. A., and Mahoud, M.

meta-synthesis (Vol. 3), Sage.

Paterson, B. L. (2001). The shifting perspectives model of chronic illness. Journal of nursing scholarship, 33(1), 21-26.

Paterson, B. L. and Thorne, S. (2003). Designer's Corner. CJNR, 35(3), 39-43.

Peterson, K. L. and Dorsey, J. A. (2000). Roadmap for integrating sustainable design into site-level operations. Pacific Northwest National Laboratory, Operated By Battelle for The United States Department of Energy, 1-96.

PMI. (1996). Project Management Body of Knowledge (PMBOK).

PMI. (2008). Project Management Body of Knowledge (PMBOK).

Public Health Resource Unit, England. Critical Appraisal Skills Programme (CASP): Making sense of evidence. 2006; Available

at: http://www.phru.nhs.uk/Doc_Links/Qualitative\%20A ppraisal \%20Tool.pdf. Accessed November/3, 2008.

Pulaski, M. H., Horman, M. J., and Riley, D. R. (2006). Constructability practices to manage sustainable building knowledge. Journal of Architectural Engineering, 12(2), 83-92.

Russell, J. S. and Swiggum, K. E. (1994). Investigation of Constructability Concepts and Tools for Highway Construction. Retrieved from.

Russell, J. S. and Swiggum, K. E. (1994). LessonsLearned and Constructability Review Databases. Retrieved from.

Saghatforoush, E. (2014). Extension of constructability to include operation and maintenance for infrastructure projects. Queensland University of Technology.

Saghatforoush, E., Trigunarsyah, B., and Too, E. G. (2012). Assessment of operability and maintainability success factors in provision of extended constructability principles.

Saldaña, J. (2015). The coding manual for qualitative researchers, Sage.

Sandelowski, M. and Barroso, J. (2006). Handbook for synthesizing qualitative research, Springer Publishing Company.

Shirpak, K., Sepali, G., and Chini Chian, M. (2010). Meta-Synthesis of qualitative research in the health sciences. Iranian Journal of Epidemiology, 6(1), 5157.

Tatum, C. (2005). Building better: technical support for construction. Journal of construction engineering and management, 131(1), 23-32.

Tatum, C., Vanegas, J. A., and Williams, J. (1987). Constructability improvement using prefabrication, preassembly, and modularization: Bureau of Engineering Research, University of Texas at Austin.

Tatum, C. B. (1987). Improving constructibility during conceptual planning. Journal of Construction Engineering and Management, 113(2), 191-207.

Tesch, D., Sobol, M. G., Klein, G., and Jiang, J. J. (2009). User and developer common knowledge: Effect on the success of information system development projects. International Journal of Project Management, 27(7), 657-664.

Trigunarsyah, B. (2001). Implementing constructability improvement into the Indonesian construction industry.

Trigunarsyah, B. and Skitmore, M. (2010). Chapter 21: The key to successful implementation: project management of sustainable infrastructure provision.
Sustainable urban and regional infrastructure development.

Voss, M. (2012). Impact of customer integration on project portfolio management and its successDeveloping a conceptual framework. International Journal of Project Management, 30(5), 567-581.

Webster's. (1913). Webster's revised unambridged dictionary: G. and C. Merriam Company.

Weed, M. (2006). Sports tourism research 2000-2004: A systematic review of knowledge and a metaevaluation of methods. Journal of Sport and Tourism, 11(1), 5-30.

Wells, J. (1986). The construction industry in developing countries: Alternative strategies for development, Taylor and Francis.

Wübbenhorst, K. L. (1986). Life cycle costing for construction projects. Long Range Planning, 19(4), 87-97.

YY Ling, F., GY Toh, B., Kumaraswamy, M., and Wong, K. (2014). Strategies for integrating design and construction and operations and maintenance supply chains in Singapore. Structural Survey, 32(2), 158182.

Zimmer, L. (2006). Qualitative meta-synthesis: a question of dialoguing with texts. Journal of advanced nursing, 53(3), 311-318.

Zolfagharian, M. and Latifi, M. (2011). Grounded theory with QSR NVivo 8. Imam Sadegh University.

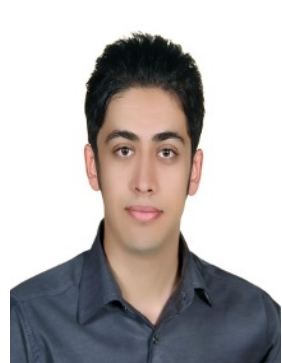

Omid Arbabi is a MSC in the Construction Engineering and Management (CEM) from Mehralborz Institute of Higher Education (MIHE). He is the gold member of the Construction and Project Management Clinic (CPMC) within the institute. His research interests include Construction Management, Building Information Modeling (BIM), Constructability, Operability and Maintainability concepts (COM).

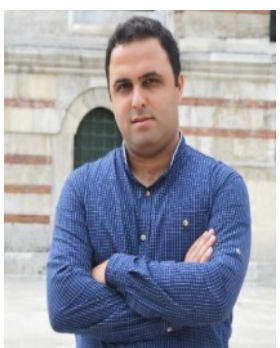

Dr. Ehsan Saghatforoush is an Assistant Professor in the Project and Construction Management (PCM) Department at Mehralborz Institute of Higher Education (MIHE). He is the founder and instructor of the Construction and Project Management Clinic (CPMC) within the institute. His research interests include Construction Management, Building Information Modeling (BIM), Integrated Project Delivery (IPD), Constructability, Operability and Maintainability concepts (COM)

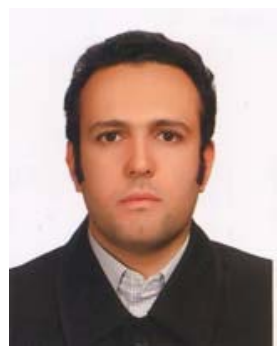

Hamidreza Athari is a $\mathrm{PhD}$ candidate in Construction Project Management at the University of Tehran. He is a BIM Manager and PMO Consultant at some Mega projects. His research interests include Building Information Modeling (BIM), PMO establishment, and Knowledge 
Management in Project-based Organizations.

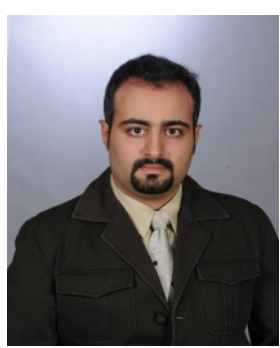

Mohammad Mahoud is a Teaching Assistant for Project Management in the Project and Construction Management (PCM) Department at Mehralborz Institute of Higher Education (MIHE). As a Management Board Member and Chairman of the IPMA Young Crew (Iran), he has gathered experience in leading a Young Crew. His research interests include Human Resource Management, Construction Management, Construction Executive Teams, Project Oriented Organization and Enterprise, Competency Models, Building Information Modeling (BIM), Integrated Project Delivery (IPD), Constructability, Operability and Maintainability concepts (COM). 